\title{
$\mathrm{ALA}$ 동적 특성 및 능동진동제어 실험
}

\section{Dynamic Characteristics of ALA and Active Vibration Control Experiment}

\author{
이 한 동*. 곽 문 규†. 김 정 훈**. 송 윤 철***. 심 재 호*** \\ Han-Dong Lee, Moon K. Kwak, Jeong-Hoon Kim, Yoon-Chul Song and Jae-Ho Shim \\ (2009년 3월 11일 접수 ; 2009년 6월 18일 심사완료)
}

\begin{abstract}
Key Words : Active Linear Actuator(능동선형구동기), Active Vibration Control(능동진동제어), Vehicle Vibration (차량진동)
\end{abstract}

\begin{abstract}
This research is concerned with the application of the active linear actuator to the active vibration control of structure. The active linear actuator will be mounted on the sub-frame so that it can cancel the excitation transferred from the engine. Accelerometer mounted on the sub-frame detects the vibration and its signal is fed into the DSP controller where the control algorithm is installed. The output of the DSP controller is connected to the driver which amplifies the DSP output. In general, the pulse width modulation power amplifier is used to drive the voice-coil type actuator. This study shows the dynamic characteristics of the active linear actuator and active vibration control experimental results.
\end{abstract}

\section{1. 서 론}

자동차에서의 안락함 분야에서 새로운 진동 제어 방법을 요구하고 있다. 특히 기존의 엔진마운트로써 더 이상의 효과를 기대하기 어렵게 됨에 따라 새로 운 개념의 능동 엔진마운트가 도입되게 되었다. 기 존의 엔진마운트 설계방식은 엔진의 진동을 자동차 메인 프레임으로부터 격리하는 방식으로 설계되었으 며 이를 위해 고무 또는 하이드로마운트가 사용되고 있다. 그러나 기존의 고무로 제작된 엔진마운트는 고주파수 대역에서 효과적이기 때문에 엔진에 의하 여 발생된 낮은 주파수 대역의 진동을 억제하는 데 는 한계가 있다 ${ }^{(1)}$. 이런 이유로 최근에 새로운 엔진 마운트에 대한 연구(1-4)가 진행되고 있다. Konrad $\mathrm{Kowalczyk}^{(3)}$ 는 자동차 프레임에 voice-coil형태의

† 교신저자; 정회원, 동국대학교 기계로봇에너지공학과

E-mail : kwakm@dongguk.edu

Tel : (02)2260-3705, Fax : (02)2263-9379

* 동국대학교 기계로봇에너지공학과

** (주) 현대자동차

*** (주) 파브코
액추에이터를 부착하고 엔진에서 전달되는 신호의 180 도 위상으로 제어력을 가하여 차량의 진동을 능 동적으로 제어할 수 있음을 보여주었다. 이 연구에 서도 이와 유사한 방법을 이용해 자동차의 프레임 진동을 억제하는 연구를 수행하였다. 이 연구에서 사용한 구동기는 active linear actuator(ALA)로 불 리는 전동식 액추에이터이다. 이 연구에서는 먼저 $\mathrm{ALA}$ 의 동특성에 대한 이론 모델링과 실험에 의한 검증을 시도하였고, 실차에 적용하기 전에 linear electro-magnetic actuator(LEMA)가 연결된 실험 장 비를 제작하여 $\mathrm{ALA}$ 에 의한 능동 진동 제어의 효용 성을 조사하였다.

이 연구에서는 먼저 자동차의 능동진동제어를 위 해 개발된 ALA의 동특성에 대한 이론 모델을 유도 하여 작동 원리를 조사하고 실험을 통해 그 성능을 검증하였다. 동특성이 파악된 ALA를 LEMA가 연 결된 구조물에 부착하여 능동진동제어를 수행하였 다. 사용한 제어 알고리즘은 속도 피드백 제어 알고 리즘으로 가속도 입력을 고려하여 적분 제어를 사 용하였다. 실험 결과는 ALA가 효과적으로 진동을 
저감시킬 수 있음을 보여준다.

\section{2. $\mathrm{ALA}$ 의 동적 모델링 및 실험}

$\mathrm{ALA}$ 는 움직이는 질량을 이용해 부착된 부위로 힘을 전달하는 관성 형태의 구동기이다. 이는 차량 의 idle상태부터 가속 후 정속구간까지 작동되도록 설계되었다. 그 동적 특성은 $\mathrm{ALA}$ 를 구성하는 요소 들에 의해 결정되는데 차량에 부착된 시스템은 간 단하게는 이자유도 스프링-질량-댐퍼 구조로 볼 수 있다. Fig. 1은 ALA이 차량 프레임에 고정된 전체 모델을 보여준다.

여기서 $m_{a}, c_{a}, k_{a}, m_{f}, c_{f}, k_{f}$ 는 각각 $\mathrm{ALA}$ 와 의 내부 질량, 댐핑계수, 스프링상수와 차량 프레임 의 질량, 댐핑계수, 스프링상수를 나타낸다. 그리고 $F_{a}$ 는 영구자석과 코일에 의해 발생한 기진력을 나 타낸다. ALA의 내부 질량의 변위와 차량 프레임의 변위를 각각 $x_{a}, x_{f}$ 라고 하면 이 모델에 대한 운동 방정식은 다음 식으로 표현된다.

$$
\begin{gathered}
m_{f} \ddot{x}_{f}+\left(c_{f}+c_{a}\right) x_{f}-c_{a} x_{a}+\left(k_{f}+k_{a}\right) x_{f}-k_{a} x_{a} \\
=-F_{a}+F_{e} \\
m_{a} \ddot{x}_{a}-c_{a} \dot{x}_{f}+c_{a} \dot{x}_{a}-k_{a} x_{f}+k_{a} x_{a}=F_{a}
\end{gathered}
$$

식 (1a)와 식 $(1 \mathrm{~b})$ 를 더하면 다음과 같은 식이 유 도된다.

$$
m_{f} \ddot{x}_{f}+c_{f} \dot{x}_{f}+k_{f} x_{f}=F_{e}-m_{a} \ddot{x}_{a}
$$

따라서 ALA가 프레임으로 전달되는 전달력은

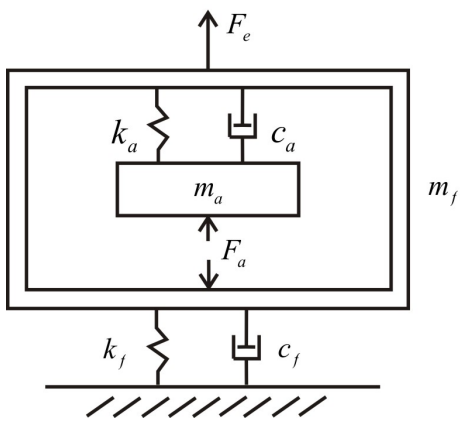

Fig. 1 Dynamic model for system
$\mathrm{ALA}$ 내부 질량과 그 질량의 가속도로 다음과 같이 결정된다.

$$
F_{T}=-m_{a} \ddot{x}_{a}
$$

영구자석과 코일에 의해 발생하는 기진력은 다음 식으로 표현된다.

$$
F_{a}=B I L
$$

여기서 $B$ 는 자기장, $I$ 는 전류, $L$ 은 코일의 길이다. 실제 제어에 있어 $\mathrm{ALA}$ 의 구동앰프에 전압 신호를 주게 되며 구동 앰프는 이 신호를 받아 전류를 제 공하게 된다. 실제로는 PWM(pulse width modulation) 방법이 사용된다. 근사적으로 가진력은 다음 과 같이 표현할 수 있다.

$$
F_{a}=\alpha_{a} V_{a}
$$

여기서 $\alpha_{a}$ 는 증폭앰프의 비례상수이며 $V_{a}$ 는 증폭앰 프에 전달되는 제어 신호이다.

$\mathrm{ALA}$ 의 전달력을 직접 계측하기 위해 프레임을 고정시키는 경우 $\left(x_{f}=0\right)$ 를 고려해 보자. 이 경우 식 (2)는 다음과 같이 유도된다.

$$
m_{a} \ddot{x}_{a}+c_{a} \dot{x}_{a}+k_{a} x_{a}=F_{a}
$$

식 (4), (5)와 (6)을 이용하면 ALA 증폭앰프에 제 공되는 전압 대비 전달력에 대한 식이 다음과 같이 표현될 수 있다.

$$
\frac{F_{T}}{V_{a}}=-\alpha_{a} \frac{s^{2}}{s^{2}+2 \zeta_{a} \omega_{a} s+\omega_{a}^{2}}
$$

여기서 $\zeta_{a}, \omega_{a}$ 는 $\mathrm{ALA}$ 의 감쇠계수와 고유진동수이다.

식 (7)로부터 $\mathrm{ALA}$ 는 고유진동수에서 가장 큰 제 어력을 발휘할 수 있음을 알 수 있다. 그러나 고유 진동수보다 낮은 진동수에서는 효력이 떨어지며 고 유진동수보다 높은 진동수에서는 제어력이 일정해 짐을 예상할 수 있다. 이와 같은 이론적 추론을 입 증하기 위해 Fig. 2와 같은 실험 장치를 구성하였다. Fig. 2에서 알 수 있듯이 $\mathrm{PCB}$ 사의 force transducer 를 바이스에 고정하고 그 위에 $\mathrm{ALA}$ 를 부착하였다. 
$\mathrm{ALA}$ 를 구동하기 위해서 아날로그 앰프와 PWM 모 터 드라이버를 연결하고 HP35670A장비를 이용해 제 어 영역 주파수인 $10 \mathrm{~Hz}$ 에서 $110 \mathrm{~Hz}$ 까지 주파수 응 답 곡선을 측정하였다. Fig. 3 은 아날로그 앰프를 사
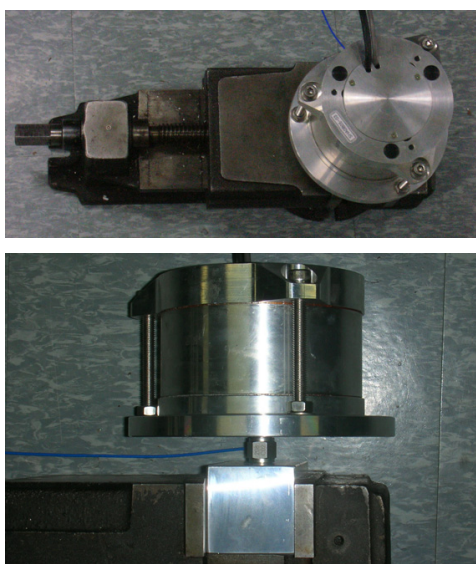

Fig. 2 Experiment setup for ALA

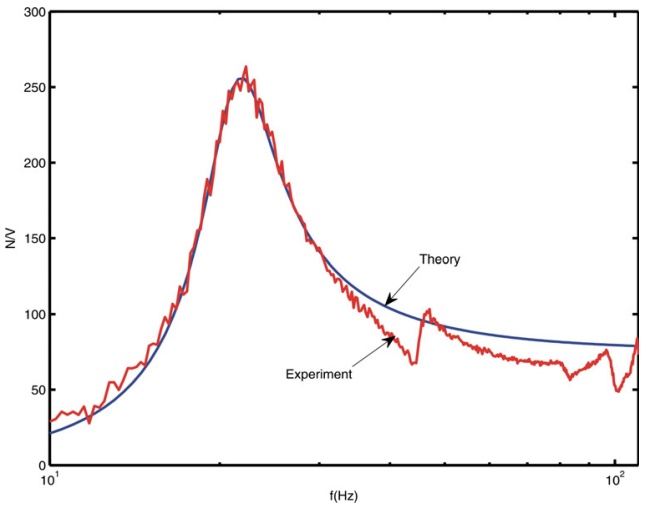

(a) Magnitude

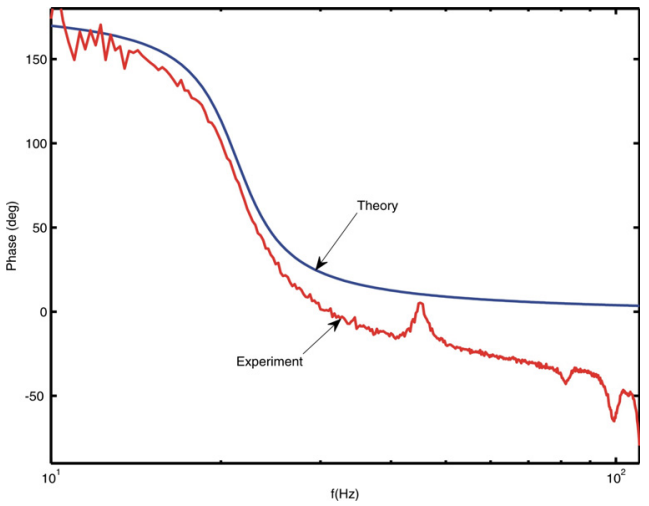

(b) Phase

Fig. 3 Transfer function of ALA
용하는 경우에 식(7)에 근거한 이론적인 전달력 주 파수 응답 곡선과 실험값을 비교한 그림이다.

Fig. 3으로부터 ALA의 동적 거동은 이론 모델로 부터 유추한 바와 유사함을 알 수 있다. 그러나 높 은 주파수에서 고차모드가 나타남을 알 수 있으며 제어력 또한 저하됨을 알 수 있다. 위상은 이론값보 다 약간 더 크게 나타남을 알 수 있다. 이는 앰프를 거쳐가면서 위상 지연이 발생하는 것으로 예상된다. 진동수가 올라갈수록 $\mathrm{ALA}$ 의 동적 특성은 이론값과 차이가 발생한다. ALA의 고유진동수는 약 $23 \mathrm{~Hz}$ 로 나타났으며 고유진동수보다 큰 진동수에서 약 100 $\mathrm{N} / \mathrm{V}$ 이상의 힘이 발생됨을 알 수 있다. 물론 이 성 능은 앰프의 성능에 의해서도 좌우된다.

\section{3. 능동 진동 제어 실험}

실제 차량의 능동진동제어는 Fig. 4와 같은 방식 으로 이루어진다. 엔진 마운트가 연결되는 서브프레 임 아래에 ALA가 부착하고 서브프레임의 가속도 신호를 이용해 제어기를 통해 적절한 제어력을 차 량 프레임에 전달하는 것이다.

Fig. 4에서 보이듯이 엔진에 의해 발생된 진동은 기존의 엔진 마운트를 통해 프레임으로 전달된다. 프레임에 장착된 가속도계는 프레임의 진동을 계측 하는데 사용된다. 그러나 프레임 진동에는 다양한 형태의 외부 잡음이 포함되기 때문에 엔진진동에 의한 신호를 계측하기 위한 필터 회로가 반드시 필 요하다. 노면의 진동 역시 타이어를 통해 프레임에 전달되어 영향을 줄 수 있다. 그러나 이 연구에서는 엔진에 의해 유발되는 진동을 억제하는 것을 목표 로 하였다.

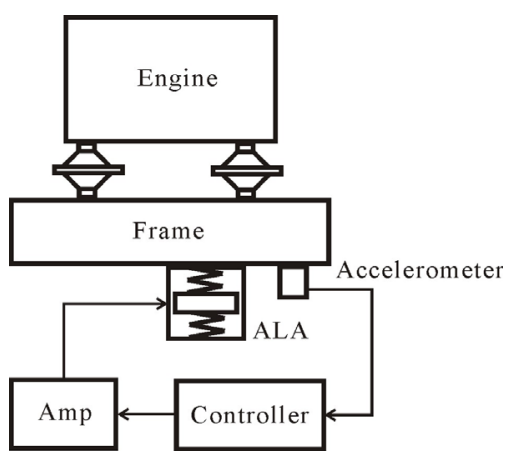

Fig. 4 Diagram for vehicle vibration reduction 
실제 차량에 대한 능동진동제어 실험을 수행하기 전에 LEMA를 이용해 능동진동제어 실험을 수행하 였다. Fig. 5는 LEMA와 구조물이 결합된 시스템을 보여준다.

Fig. 5에서 볼 수 있듯이 LEMA 시스템에 고무 마운트로 지지되는 강판을 연결하고 강판의 상부에 가속도계와 ALA를 부착하였다. Fig. 6은 ALA와 가속도계가 부착된 모습을 보여준다. Fig. 5의 시스 템은 Fig. 7로 다시 표현할 수 있다. LEMA 시스템 의 축에 연결된 상판에 ALA가 부착되어 있고 여기 에 가속도계도 부착되어 있다. 상판은 자동차의 프 레임에 해당되며 LEMA는 엔진마운트를 통해 전달 되는 가진력에 해당된다.

LEMA, 가속도계, ALA가 부착된 구조물의 동적 특성을 파악하기 위해 LEMA에 FFT 신호 출력을

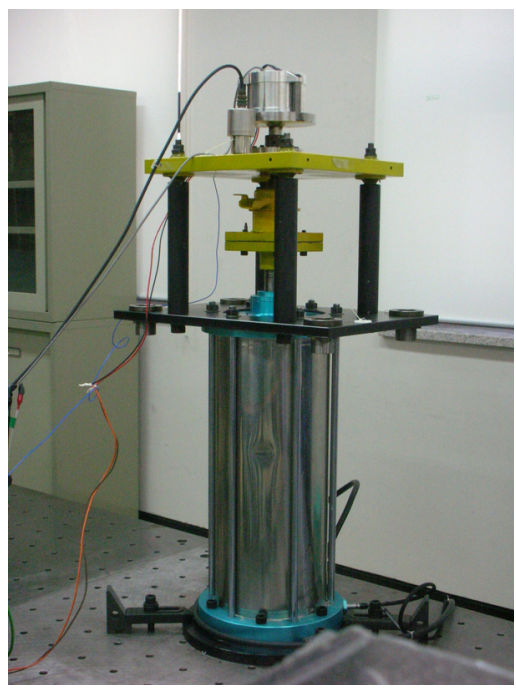

Fig. 5 LEMA system for active vibration control experiment

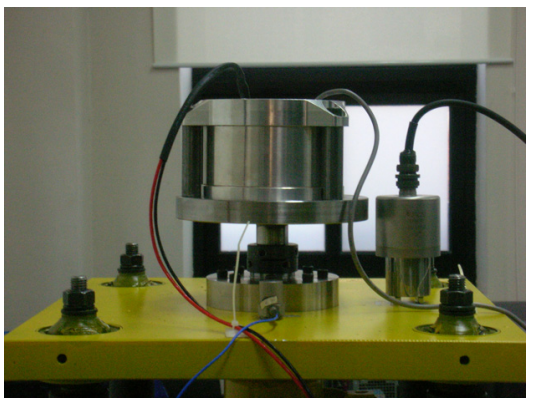

Fig. 6 ALA and accelerometer mounted on plate
연결하고 가속도 신호를 FFT 입력에 연결하여 전 달함수를 계측하였다. Fig. 8은 계측된 주파수 응답 곡선을 보여준다. 구축된 구조물은 $70 \mathrm{~Hz}$ 에서 공진 이 발생함을 알 수 있는데 실제 자동차의 대부분의

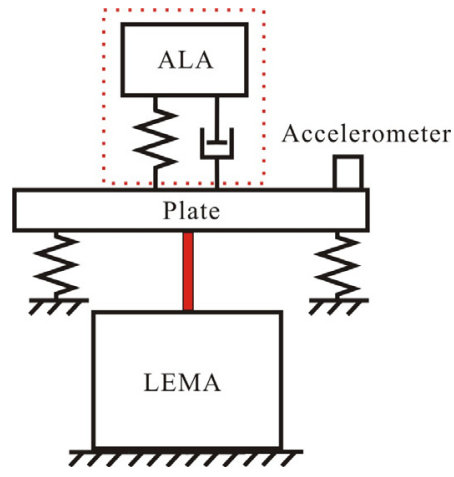

Fig. 7 Experimental setup for active vibration control using ALA and LEMA

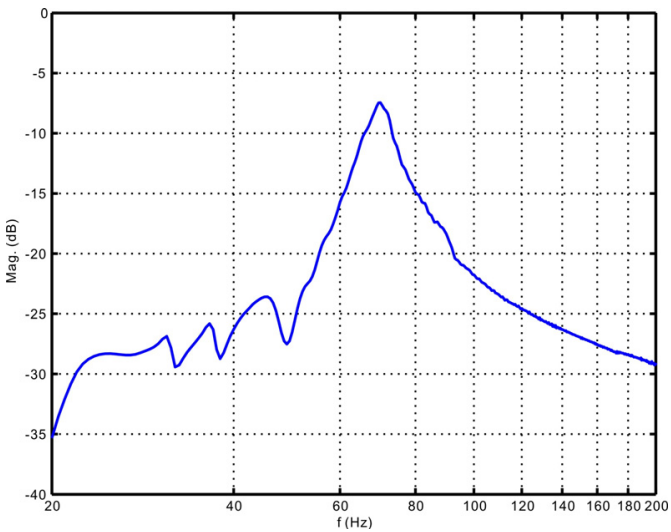

(a) Magnitude

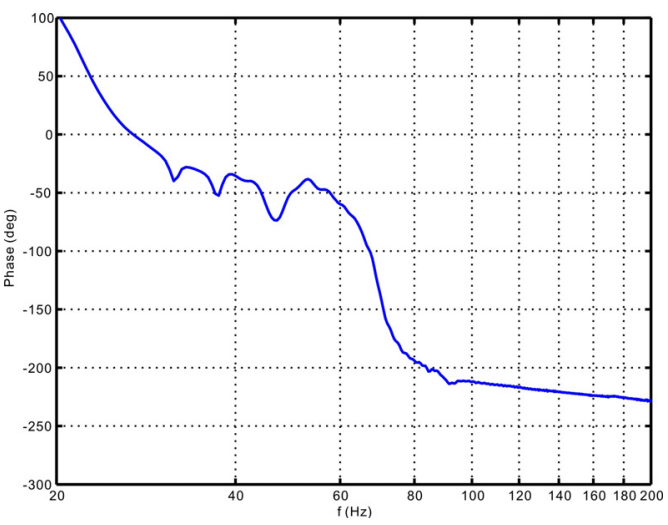

(b) Phase

Fig. 8 Frequency response function of structure 
공진대역은 $40 \mathrm{~Hz}$ 이하인 점과는 차이가 있다 ${ }^{(8)}$. 고 유진동수가 높게 나타난 이유는 상판을 지지하고 있는 고무 스프링의 강성이 높고 상판의 질량이 작 기 때문이다. 이 실험의 목적은 $\mathrm{ALA}$ 의 진동제어 가능성에 대한 것이기 때문에 실제 차량과 다른 동 적 특성이 문제가 되지 않았다.

앞에서 언급하였듯이 이 연구에서는 피드백 제어 알고리즘을 시험하였다. 능동진동제어를 수행하는데 피드백 제어 블록 다이어그램은 Fig. 9 와 같다.

여기서 외부교란은 엔진에 의해 발생한 기진력을 나타내며 가속도계를 이용하여 계측된 신호를 제어 알고리즘을 거쳐 제어 신호를 ALA에 제공하는 전 형적인 피드백 시스템 구성이다. 제어 알고리즘을 적용하기 위해 dSpace사의 DS1104 제어보드를 사 용하였다. 제어 알고리즘은 simulink를 이용해 구현 하였다. Fig. 10은 이 실험에 사용된 적분 제어 알 고리즘을 보여주고 있다. 가속도 신호를 적분하여 사용하기 때문에 실제 능동진동제어 알고리즘은 직 접 속도 피드백 제어에 해당된다.

또한 신호 필터링을 위해 저주파수통과 필터와

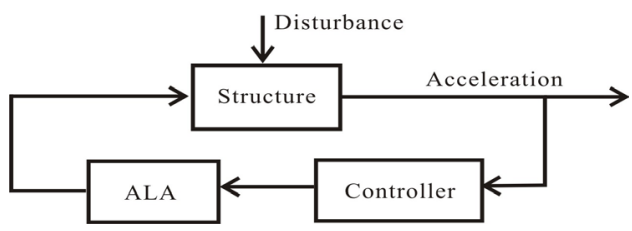

Fig. 9 Active vibration control loop
고주파수통과 필터를 사용하여 밴드패스 필터를 구 현하였다. ALA구동은 앞 선 실험에서 사용된 PWM 방식의 모터드라이버를 사용하였는데 이 모터 드라 이버의 최대 허용전류는 $25 \mathrm{~A}$ 이다. $\mathrm{DA}$ 변환 과정에 서 0.25 가 더해진 이유는 사용한 구동 앰프가 기준 전압 $2.5 \mathrm{~V}$ 를 기준으로 $0 \sim 5 \mathrm{~V}$ 입력 전압을 받아 구 동하기 때문이다. 즉, $2.5 \mathrm{~V}$ 보다 낮으면 -, $2.5 \mathrm{~V}$ 보 다 크면 + 값으로 구동한다.

실제 자동차의 엔진에 의해 유발되는 기진력은 $\mathrm{RPM}$ 과 관련된 특정 주파수 성분을 가지게 된다. 이 기진력은 엔진마운트를 통하여 프레임에 전달된 다. 실제 차량의 경우 엔진마운트가 기진력의 대부 분을 흡수하게 되어 프레임에서 발생되는 진동은

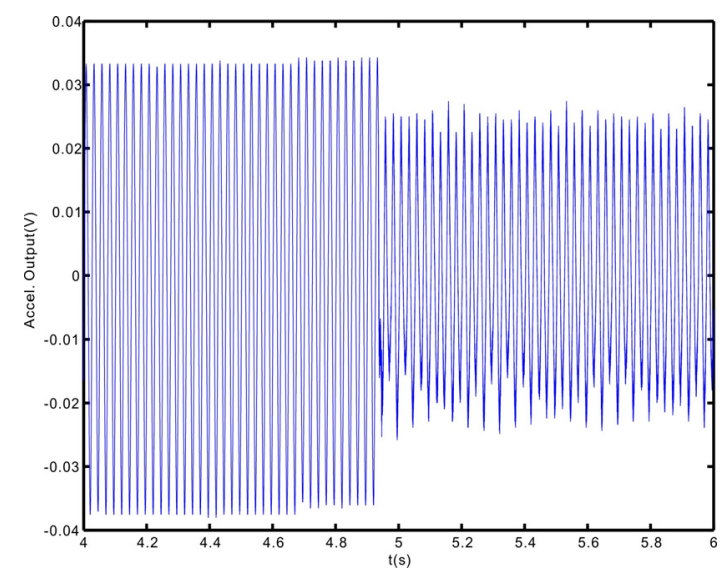

Fig. 11 Time history at $40 \mathrm{~Hz}$ excitation

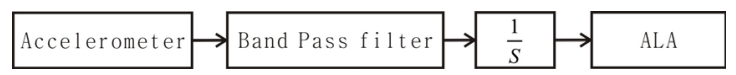

(a)

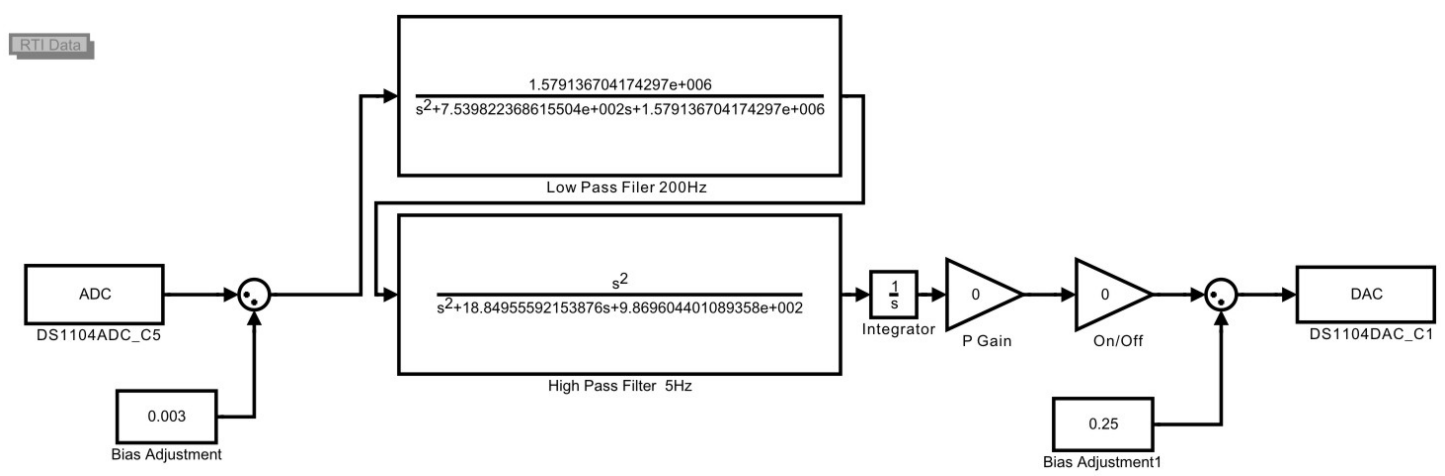

(b)

Fig. 10 A brief block diagram (a) and simulink block (b) for integral control 


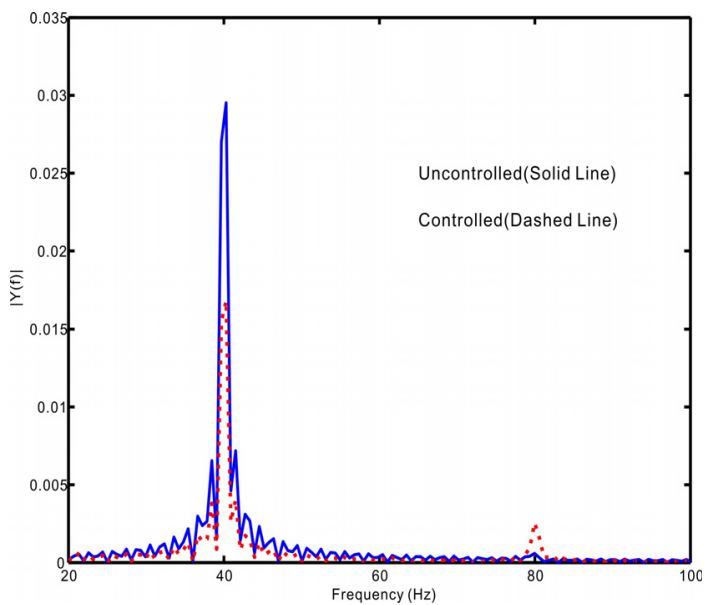

Fig. 12 FFT analysis at $40 \mathrm{~Hz}$ excitation

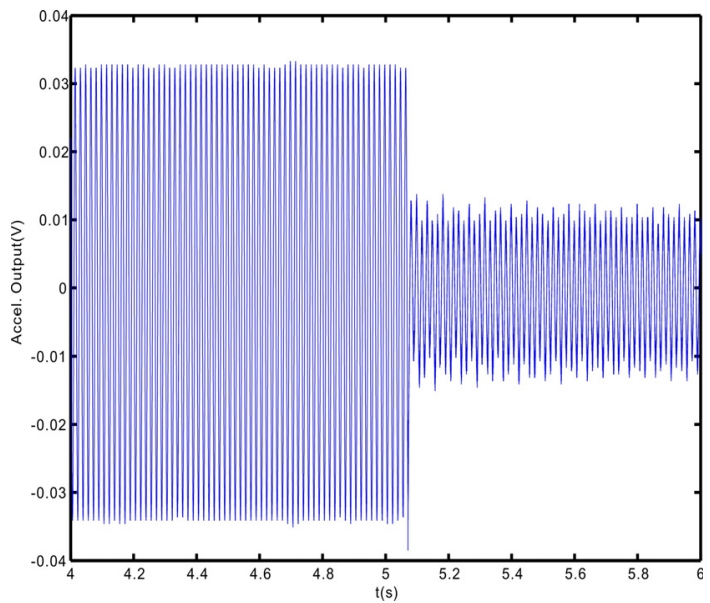

Fig. 13 Time history at $60 \mathrm{~Hz}$ excitation

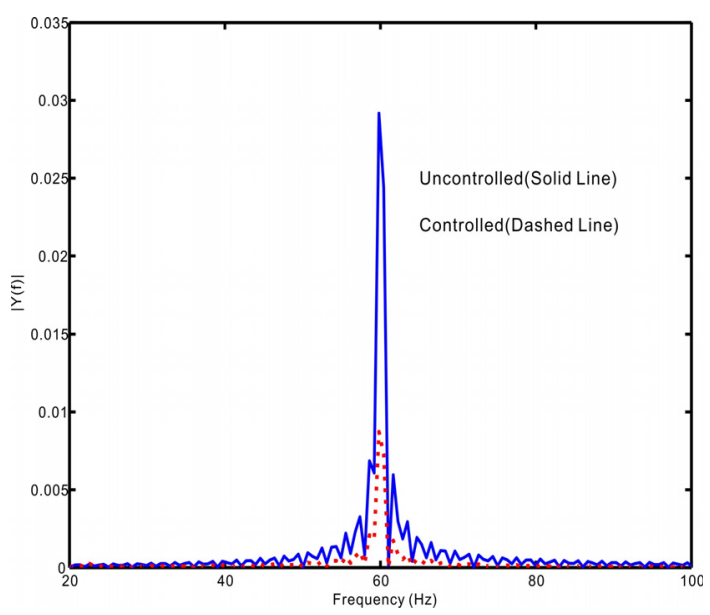

Fig. 14 FFT analysis at $60 \mathrm{~Hz}$ excitation

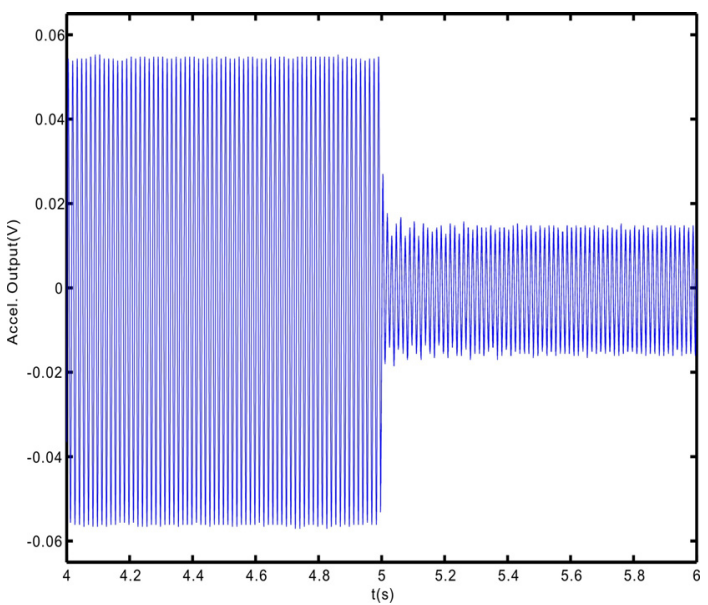

Fig. 15 Time history at $70 \mathrm{~Hz}$ excitation

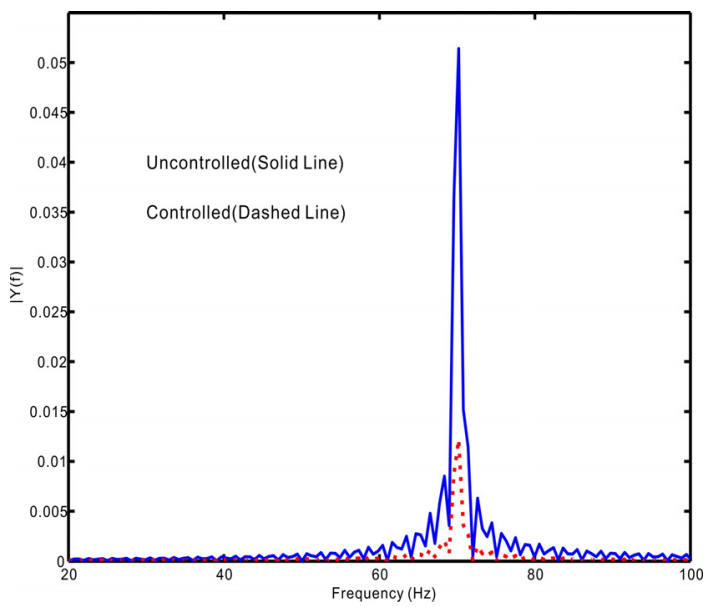

Fig. 16 FFT analysis at $70 \mathrm{~Hz}$ excitation

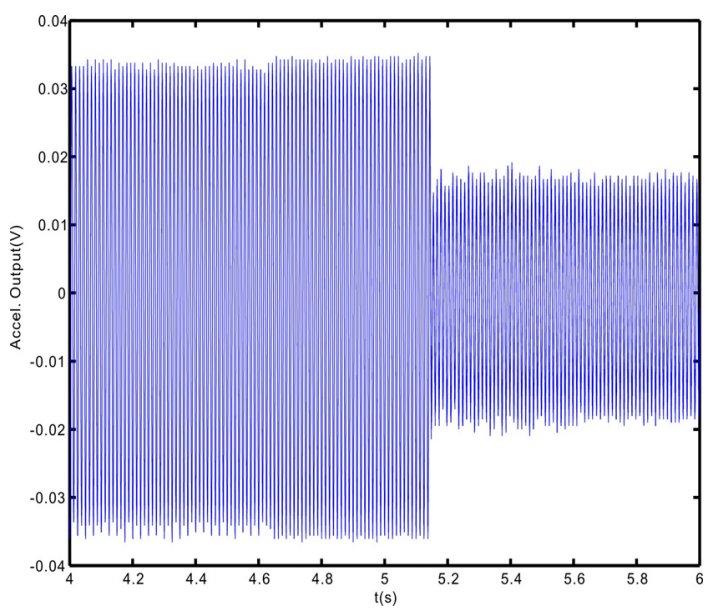

Fig. 17 Time history at $80 \mathrm{~Hz}$ excitation 


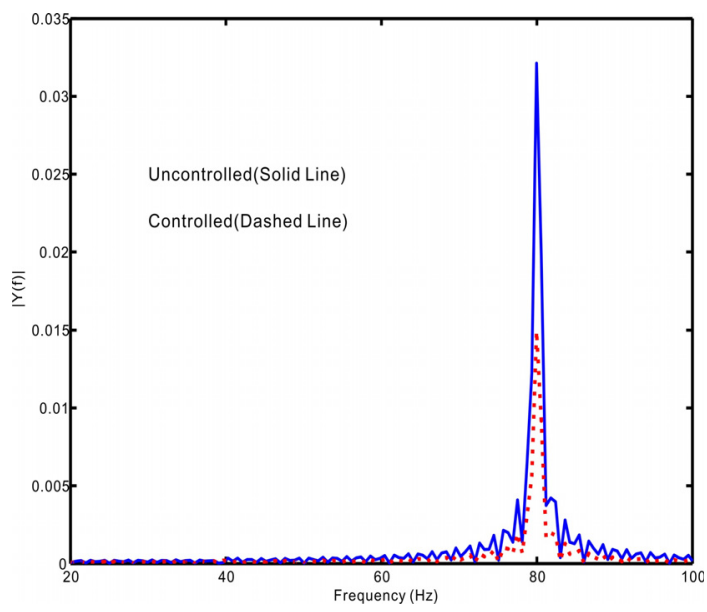

Fig. 18 FFT analysis at $80 \mathrm{~Hz}$ excitation

\section{크지 않다.}

능동진동제어 실험을 위해 $40,60,70,80 \mathrm{~Hz}$ 를 가진 주파수로 하여 LEMA를 구동하였고 약 5 초후 에 제어기를 가동시켰다. Figs. 11 18은 각 외부 가 진에 따른 능동진동제어 응답과 주파수 분석을 보 여주고 있다.

Figs. 11 18에서 알 수 있듯이 전반적으로 능동진 동제어기를 가동할 경우 진동이 저감됨을 알 수 있 다. $40 \mathrm{~Hz}$ 에서의 진동 저감 성능이 다른 주파수에 대 한 제어 효과에 비해 약간 낮게 나타났는데 이는 각 주파수대의 동특성이 변하기 때문인 것으로 보인다.

\section{4. 결 론}

이 연구에서는 능동엔진마운트 시스템에 필요한 $\mathrm{ALA}$ 구동기에 대한 동적 모델링과 동특성 실험을 수행하고 LEMA가 연결된 구조물에 대해 능동진동 제어 실험을 수행하였다. 실험 결과 다음과 같은 결 론을 얻었다.

(1) $\mathrm{ALA}$ 의 동특성은 이론에서 예상한 동특성을 보여준다. ALA의 공진주파수에 제어주파수를 맞추 는 경우 최대의 효과를 얻을 수 있지만 차량의 $\mathrm{RPM}$ 이 변하기 때문에 제어기 설계시 $\mathrm{ALA}$ 의 동특 성을 고려하여야 한다.

(2) 차량의 엔진에 의한 가진을 LEMA 시스템을 이용하여 구현하고 능동진동제어를 수행한 결과 ALA가 실차의 능동진동제어에 활용 가능함을 확인 하였다.

\section{후 기}

이 연구는 지식경제부 부품소재기술개발사업 “능 동형 엔진 마운팅 시스템 개발” 과제의 일환으로 수행되었다. 관계자 여러분께 감사드린다.

\section{참 고 문 헌}

(1) Persson, P., Johansson, S., Hakansson, L., Claesson, I. and Samuels, T., 2001, "Feedback-LMS Control of Lateral Vibration in a Traincar," The 8th International Congress on Sound and Vibration, Hong Kong.

(2) Karimi, H. R. and Lohmann, B., 2007, "Haar Wavelet Based Robust Optimal Control for Vibration Reduction of Vehicle Engine-body System," Electrical Engineering, Vol. 89, pp. 469 478.

(3) Kowalczyk, K., Karkosch, H. J., Marienfeld P. M. and Svaricek, F., 2006, "Rapid Control Prototyping of Active Vibration Control System in Automotive Application," Proceedings of the IEEE, pp. 2677 2682.

(4) Olsson, C., 2006, "Active Automotive Engine Vibration Isolation using Feedback Control," Journal of Sound and Vibration, Vol. 294, pp. 162 176.

(5) Fowler, L. P., 1996, "Application of Filtered-X LMS Algorithm for Disturbance Rejection in Timeperiodic Systems," MS Thesis, Virginia Polytechnic Institute and State University.

(6) Olsson, C., 2006, "Active Automotive Engine Vibration Isolation Using Feedback Control," Journal of Sound and Vibration, Vol. 294, pp. 162 176.

(7) Ang, K. H. and Chong, G., 2005, "PID Control System Analysis, Design and Technology," IEEE Transactions on Control Systems Technology, Vol. 13, No. 4, pp. 559 576.

(8) Lee, K., Jung, S. and Kim, J., 2008, "Full Vehicle Modal Testing Using Single-Run FRF Measurement and Mode Map Validation," Proceedings of the KSNVE Annual Autumn Conference, pp. 387 388. 